\title{
NUTRITIONAL STATUS AND NUTRITIONAL SUPPORT IN CHILDREN WITH CONGENITAL MALFORMATIONS OF BRAIN IN UKRAINE: SINGLE-CENTER OBSERVATIONAL DESCRIPTIVE CROSS-SECTIONAL STUDY
}

\author{
Riga O., Orlova N., Ishchenko T. \\ Kharkiv National Medical University, Kharkov, Ukraine \\ https://doi.org/10.35339/ic.7.2.94-101
}

\begin{abstract}
In Ukraine, as one of the income and middle income countries (LMICs), PEM is detected and diagnosed not quite actively especially in children with neurologic impairment. Methods: Nutritive status and energy consumption was evaluated in 17 young and preschool children with congenital malformations of brain by anthropometry, 24-hour dietary recall and questionnaire of caregivers. Results: The study demonstrated nutritional disorders: Z-score $\mathrm{BW}$ for age in total cohort was $-3.2, \mathrm{H} / \mathrm{L}$ for age was -2.7 . The moderate PEM was diagnosed in $2 / 17$ children, severe PEM in 12/17. The late appointment of nutritional support to such children was demonstrated, its effect on increasing growth and body weight was detected. Conclusion. The importance of drawing up individual plans for the energetic consumption of the children with congenital malformations of brain with training of caregivers and rehabilitative and palliative team is advisable.
\end{abstract}

Keywords: children, protein-energy malnutrition, congenital malformations of brain, LMICs.

\section{Introduction}

Nutrition problems are common in children with neurological impairment $[1,2]$. Causes of protein-energy malnutrition (PEM) in them are multifactorial, and malnourishment may be due to motor disorders, digestive problems, medicine use, and the social environment [3].

PEM is one of the most serious medical problems around the world. According to the WHO research, in $22-35 \%$ of children from poor families aged $2-6$ years, the body weight (BW) is below the $5^{\text {th }}$ percentile, the growth of $11 \%$ of children is below the 5 th percentile. In hospitalized children, various forms of PEM are still common, which aggravates the course of the disease, worsens their prognosis, and causes a delay in the physical and neurological development of children [4].

In Ukraine, as one of low income and middle income countries (LMICs), PEM is detected and

Corresponding Author:

Natalia Orlova, MD, PhD student, Department

of Pediatrics 1 and Neonatology,

Kharkiv National Medical University,

E-mail: norlova318@gmail.com diagnosed not quite actively especially in children with neurologic impairment. Some recent publications demonstrate actuality and research of this problem in other countries such as Bosnia and Herzegovina, Nigeria and Ghana $[3,5,6]$.

The main clinical requirements for the assessment of PEM in children is the rapid process of identifying people from the nutritional risk group, which is carried out using developer questionnaires and using appropriate validated scales $[7,8]$. The standard method for detecting PEM is the assessment of physical development in children [9].

Assessment of physical development is not always a simple task for children with cerebral palsy (CP) and similar neurodegenerative disorders [3]. Anthropometric evaluation can become a stumbling block in the assessment of the physical development of children with neurological impairment. BW and height or length $(\mathrm{H} / \mathrm{L})$, obtained under certain conditions, are often not accurate. Measuring the $\mathrm{H} / \mathrm{L}$ of lying children is unreliable if the baby has a contracture, high tone of muscles, scoliosis, which interferes with optimal positioning $[3,10]$. Despite this, there are more problems in the nutritional status in children 
with neurological disorders. Among them is low awareness of parents and community specialists, low accessibility to clinical nutrition products, due to their high cost, barriers to monitoring experience and nutritive support (NS) among medical personnel as a routine practice in LMICs [6]. Our study was undertaken to assess the nutritional status and nutritional support of children with congenital malformations of brain in Ukraine in order to draw attention to this problem in the community and share our experience.

2. Purposes, subjects and methods:

2.1. Objective: Assessment of nutritional status and nutritional support in children with congenital malformations of the brain.

Hypothesis: nutritional support in children with congenital malformations of the brain has no influence on physical development in children with congenital malformations of brain.

\subsection{Subjects \& Methods}

Study design and setting

A single-center observational descriptive cross-sectional study was performed. It had been carried out in Kharkiv National Medical University and Communal Non-Commercial Enterprise of Kharkiv Regional Council "Regional Specialized Baby Home «Hippocrates»" during 2019. The anthropometric assessment of the children, evaluation of oromotor dysfunction (OMD), a 24-hr dietary recall, assessment of nutritional status before ("baseline") and after 6 months of implementing of food modification ("endline") were studied.

Ethical approval

This study was authorized by the Ethics Committee of Kharkiv National Medical University (Record No. 9 dated 16 October 2018). Informed written consent was obtained from each caregiver in advance of the research. The agreement on implementing food modification (clinical nutrition) was obtained from 9 caregivers.

Sampling

Seventeen children were recruited for the study (young children and pre-schoolers) staying in the department of Palliative Care due to congenital malformations of the brain from May 2019 till October 2019. There were 9 (53\%) young children ( $0-36$ months) and $8(47 \%)$ preschoolers (3-6 years). The average age was $3.6 \pm 2.1$ years. Inclusion criteria were children of 0-6 years old with congenital malformations of brain and their caregivers. Children without congenital malformations of brain and their caregivers, children with genetic syndromes and those who did not agree to participate in the study were excluded from the study. All caregivers were females.

Data collection

For nutritional status investigation the anthropometric assessment was used. Anthropometry was measured in accordance with the standard procedure. BW was measured using a digital weighing Infant Scale and was recorded to the nearest decimal place $(0.1 \mathrm{~kg})$. The $\mathrm{H} / \mathrm{L}$ was estimated by means of Infant Length Board marked in $\mathrm{cm}$ and nearest $0.1 \mathrm{~cm}$ was recorded. For children with paralytic syndromes the $\mathrm{H} / \mathrm{L}$ was determined by measuring the length of the big tibia $(\mathrm{cm})$ and calculated by formula due to inability to stand, scoliosis or joint contractures of patients.

Body length was calculated as $(3.26 \times$ length of the big tibia) $+30.8[10,11]$

The BW $(\mathrm{kg})$, and $\mathrm{H} / \mathrm{L}(\mathrm{cm})$ was carried out in accordance with the Z-scores, using the calculators based on the WHO reference data for infants and children [12, 13]. Z-score curves were used for determination of the severity of PEM following the WHO recommendations (1999) [14].

Individual programs for nutritional support for children and caregivers were proposed as well as training with rehabilitative and palliative team

The anthropometric data and severity of PEM were recorded in two point "baseline" and after 6 months "endline" where nutritional support was carried out.

Additionally the nutritional status included investigation of a 24-hr dietary recall and questionnaire of caregivers. The following questions were included: 1 . Does the child usually eat alone or with others? 2. When does the child eat? (Are the meals regular, how many times per day?) 3. Is there sufficient time for feeding? (Does the meal last more or less than 30 minutes?) 4. Do you apply special feeding (If no, what food do you choose?).

The calculation of the main (basal) metabolism in children ( $\mathrm{kcal} /$ day) was performed according to Schofield W.N. (1985) by sex, age, $\mathrm{BW}, \mathrm{H} / \mathrm{L}$ taking into account the main conversion factors, as well as determining the true energy needs in "baseline" and after 6 months "endline" $[9,15]$. The energy nutritional deficiencies in "baseline" were corrected by food modification (clinical nutrition) during 6 months. The anthropometric data was compared in children with food modification and without food modification in 6 months. We also compared BW and $\mathrm{H} / \mathrm{L} \mathrm{Z}$-score in children depending on age 
(young and preschoolers), and the severity of motor impairment by Gross Motor Function Classification System (GMFCS), and degree of OMD as "mild" degree (eats chopped or mashed food); "moderate" (requires very mushy, chopped or liquid food); "severe" (requires a dense liquid, puree or needs feeding through a tube). The length of daily feeding time (less than 3 hours and more than 3 hours) and meal time (less than $30 \mathrm{~min}$ ) were estimated $[3,16,17]$.

The individual programs of nutritional support for children and caregivers were proposed as well as training by rehabilitative and palliative team.

\section{Analysis}

The database for the evaluation of physical development in children was created using Excel for Windows application package (StatSoft Inc.). The analysis of the test results was carried out using standard statistical methods of Statistica 7.0 package: descriptive analysis, difference between two proportions. For nonparametric comparison of independent group Mann-Whitney test $(M W)$ was used. In dependent group, the Wilcoxon Rank Sum test $(W)$ was used to verify the null hypothesis saying that population in two points, "baseline" and "endline", have the same continuous distribution with power calculation. For all statistical methods, $\mathrm{p}<0.05$ was considered statistically significant.

Conflicts of Interest: The authors declare no conflict of interest.

\section{Results}

3.1 Demographic, Clinical and Feeding Data

Table 1 presents demographic and clinical characteristics of children. The sample included 9 males and 8 females. There were 14/17 children with paralytic syndromes (I-V level of GMFCS). Severe cognitive impairment was established in $8 / 17$. Prevalence of OMD was in total sample, and was distributed as "mild" in 2/17 children, "moderate" in 4/17 and "severe" in 11/17 children. Severe OMD was associated with microcephaly, cognitive impairment and V level of GMFCS.

The feeding time was different in 5 tube-fed children compared with 12 bottle-fed or spoonfed 12 children (median 11 min vs $32 \mathrm{~min}$ ). There were no significant differences in correlation of OMD severity, sex or age.

3.2 Anthropometric data, observation of feeding and energy consumption

The results of caregivers' answers for questionnaire demonstrated that all children had meals alone without any social component, regularly, minimum 4 times, maximum 6 times per day. None of them were applied any special feeding formula. The meals length in 4 tube fed children was even less than $15 \mathrm{~min}$. The 24-hr dietary recall demonstrated that only 3 children (younger than 1 year) received formula for feeding, others - "adult" meal (porridges, vegetables, milk and meat, pureed by texture modifications for consistency). All children were unable to feed themselves and needed some feeding assistance.

Table 2 demonstrates individual nutrition status and energy intake for children in "baseline" and "endline" study depending on nutritional support (clinical nutrition). The energy intake in "baseline" means a domestic diet before NS, the energy intake in "endline" was corrected in accordance with the calculation of the basal exchange by Schofield W.N. (1985) taking into account individual child factors (growth and development; PEM; motor activity; impairments as tracheostomy, colostomy, gastrostomy; spasticity; convulsions; rehabilitation) $[9,15]$.

The moderate PEM was diagnosed in 2/17 children, severe PEM in 12/17 from the total cohort in "baseline" study. The distribution of PEM degree in "endline" was the following: moderate PEM was found in 5/17 children, severe PEM in 9/17.

Our data was collected to compare the children with NS and without NS. The children with NS had much severe deviation of Z-score BW for age at "baseline" (median -6.2 vs -2.1) (MW test $\mathrm{p}=0.0111$ ). We did not find any significant difference in Z-score deviation of $\mathrm{H} /$ $\mathrm{L}$ for age (median -2.7 vs -34) (MW test $\mathrm{p}=0.7429$ ). The median of $\mathrm{Z}$-score $\mathrm{BW}$ for age in total cohort was -3.2 [minimum - 0.5 maximum -10.4 ], of $\mathrm{H} / \mathrm{L}$ for age was -2.7 [minimum -0.5 maximum -7.1]. Among children who did not receive NS $2 / 8$ children with loss of BW and 1/8 children with loss of $\mathrm{H} / \mathrm{L}$. In children who received NS $1 / 9$ children with loss of BW and 4/9 children with loss of $\mathrm{H} / \mathrm{L}$. This suggests that a 6-month period with NS for PEM is not enough and requires further monitoring.

We found a significant difference in changes of Z-score BW for age in children under NS during 6 mo "baseline" and "endline" (median -6.2 vs -5.4 ) (W test $p=0.0208$ ) and no significant difference in changes of $\mathrm{Z}$-score $\mathrm{H} / \mathrm{L}$ for age in children under NS during 6 mo "baseline" and "endline" (median -3.4 vs -3.4) (W test $\mathrm{p}=1.0$ ).

To correct PEM in children with congenital malformations of the brain, speech therapists and physical therapists were involved as members of the multidisciplinary team. We proposed the training staff for monitoring the nutritional status in children with PEM and involvement of caregivers. 
Basic demographic and clinical data

Table 1

\begin{tabular}{|c|c|c|c|c|c|c|}
\hline$N$ & Age & Sex & GMFCS & OMD degree & Diagnosis & $\begin{array}{c}\begin{array}{c}\text { Comorbid } \\
\text { factors }\end{array} \\
\end{array}$ \\
\hline 1 & 7 yrs & $M$ & V & Moderate & $\begin{array}{c}\text { Congenital } \\
\text { hypoplasia of the } \\
\text { cerebellum }\end{array}$ & $\begin{array}{c}\text { Swallowing disorders, } \\
\text { contractures, anticonvulsant } \\
\text { therapy }\end{array}$ \\
\hline 2 & $7 \mathrm{yrs}$ & M & V & Severe & Microcephaly & $\begin{array}{l}\text { Sialorrhea, swallowing } \\
\text { contractures, cognitive } \\
\text { impairment, anticonvulsant } \\
\text { therapy, tube feeding }\end{array}$ \\
\hline 3 & 4 yrs 7 mo & $F$ & V & Moderate & Microcephaly & $\begin{array}{l}\text { Swallowing disorders, cognitive } \\
\text { impairment contractures, } \\
\text { anticonvulsant therapy }\end{array}$ \\
\hline 4 & 7 yrs & M & V & Severe & Microcephaly & $\begin{array}{c}\text { Sialorrhea, swallowing disorders, } \\
\text { contractures, cognitive } \\
\text { impairment, tube feeding }\end{array}$ \\
\hline 5 & 4 yrs 7 mo & M & III & Moderate & Microcephaly & $\begin{array}{l}\text { Colostoma, } \\
\text { gastrostoma }\end{array}$ \\
\hline 6 & 6 yrs $11 \mathrm{mo}$ & $F$ & V & Severe & $\begin{array}{c}\text { Congenital } \\
\text { hydrocephalus }\end{array}$ & $\begin{array}{c}\text { Sialorrhea, swallowing disorders, } \\
\text { contractures, cognitive } \\
\text { impairment, anticonvulsant } \\
\text { therapy }\end{array}$ \\
\hline 7 & 6 yrs 4 mo & $\mathrm{F}$ & V & Severe & Microcephaly & $\begin{array}{c}\text { Sialorrhea, swallowing disorders, } \\
\text { contractures, cognitive } \\
\text { impairment anticonvulsant } \\
\text { therapy }\end{array}$ \\
\hline 8 & 7 yrs & M & V & Severe & Microcephaly & $\begin{array}{l}\text { Sialorrhea, swallowing disorders, } \\
\text { contractures, cognitive } \\
\text { impairment tube feeding, } \\
\text { anticonvulsant therapy }\end{array}$ \\
\hline 9 & 2 yrs 2 mo & $F$ & V & Severe & $\begin{array}{c}\text { Congenital } \\
\text { hydrocephalus }\end{array}$ & $\begin{array}{l}\text { Sialorrhea, swallowing disorders, } \\
\text { contractures, cognitive } \\
\text { impairment, tube feeding, } \\
\text { anticonvulsant therapy }\end{array}$ \\
\hline 10 & 2 yrs $7 \mathrm{mo}$ & $M$ & IV & Moderate & $\begin{array}{l}\text { Congenital } \\
\text { hypoplasia of the } \\
\text { cerebellum }\end{array}$ & $\begin{array}{c}\text { Swallowing disorders, } \\
\text { gastrostomy }\end{array}$ \\
\hline 11 & 2 yrs $11 \mathrm{mo}$ & $F$ & I & No & $\begin{array}{c}\text { Congenital } \\
\text { hydrocephalus }\end{array}$ & Colostomy \\
\hline 12 & $6 \mathrm{mo}$ & $\mathrm{F}$ & - & Severe & $\begin{array}{l}\text { Congenital } \\
\text { hydrocephalus }\end{array}$ & $\begin{array}{l}\text { Tracheostomy, swallowing } \\
\text { disorders, tube feeding, }\end{array}$ \\
\hline 13 & $1 \mathrm{yr} 1 \mathrm{mo}$ & $F$ & III & Severe & Microcephaly & $\begin{array}{l}\text { Swallowing problem, tube } \\
\text { feeding, fetal alcohol syndrome }\end{array}$ \\
\hline 14 & $1 \mathrm{yr} 4 \mathrm{mo}$ & M & II & Mild & $\begin{array}{l}\text { Dandy-Walker } \\
\text { malformation }\end{array}$ & $\begin{array}{c}\text { Swallowing disorders, cleft palate, } \\
\text { fetal alcohol syndrome, } \\
\text { anticonvulsant therapy }\end{array}$ \\
\hline 15 & 1 yr 5 mo & M & II & Mild & Microcephaly & Cognitive impairment \\
\hline 16 & $5 \mathrm{mo}$ & M & - & Severe & $\begin{array}{c}\text { Ventriculomegal } \\
y\end{array}$ & $\begin{array}{l}\text { Swallowing disorders, tube } \\
\text { feeding, anticonvulsant therapy }\end{array}$ \\
\hline 17 & $6 \mathrm{mo}$ & $\mathrm{F}$ & - & No & $\begin{array}{c}\text { Congenital } \\
\text { hydrocephalus }\end{array}$ & Swallowing disorders \\
\hline
\end{tabular}

M - male; F - female; yr - year; mo - month; GMFCS - Gross Motor Function Classification System; tube - nasogastric tube.

\section{Discussion}

The published studies associate neurological impairment in children with PEM [1-3, 6, 9]. PEM is an inadequate nutrition of a child characterized by termination or slowing of increase of body weight, progressive decrease in the subcutaneous basis, violation of body proportions, digestive functions, metabolism, relaxation of specific, nonspecific protective forces, propensity to other diseases, delayed physical and psychomotor development [18-20].

Clinical presentation and diagnosis of the PEM are recorded on the basis of an assessment of the physical development of the child by the 
Table 2

Z-score of $B W$ and $H / L$ and energy intake in children with congenital malformations of brain during 6 months with and without of nutritional support

\begin{tabular}{|c|c|c|c|c|c|c|c|}
\hline \multirow{3}{*}{$N$} & \multirow{3}{*}{$\begin{array}{l}\text { NS/ } \\
\text { NA }\end{array}$} & \multirow{3}{*}{$\begin{array}{c}\text { Baseline } \\
\begin{array}{c}\text { Kcal/kg } \\
\text { day }\end{array}\end{array}$} & \multirow{3}{*}{$\begin{array}{c}\text { Endline } \\
\begin{array}{c}\text { Kcal/kg } \\
\text { day }\end{array}\end{array}$} & \multicolumn{2}{|c|}{ Baseline } & \multicolumn{2}{|c|}{ Endline } \\
\hline & & & & \multicolumn{4}{|c|}{ Z-score } \\
\hline & & & & BW for age & $\begin{array}{l}\text { H/Lt for } \\
\text { age }\end{array}$ & $\begin{array}{l}\text { BW for } \\
\text { age }\end{array}$ & $\begin{array}{c}H / L \text { for } \\
\text { age }\end{array}$ \\
\hline 1 & NA & 106 & 109 & -0.5 & -4.6 & -0.3 & -5.0 \\
\hline 2 & NS & 100 & 134 & -2.2 & -4.0 & -2.0 & -3.4 \\
\hline 3 & NS & 116 & 122 & -9.2 & -0.9 & -7.0 & -0.3 \\
\hline 4 & NS & 145 & 159 & -4.2 & -5.8 & -2.9 & -6.0 \\
\hline 5 & NS & 122 & 171 & -6.2 & -4.4 & -1.6 & -4.6 \\
\hline 6 & NA & 104 & 114 & -1.8 & -3.2 & -2.2 & -2.8 \\
\hline 7 & NS & 128 & 157 & -6.3 & -0.7 & -5.4 & -2.1 \\
\hline 8 & NS & 121 & 122 & -10.4 & -2.3 & -8.7 & -1.9 \\
\hline 9 & NS & 112 & 120 & -0.8 & -1.7 & -0.1 & -1.6 \\
\hline 10 & NS & 150 & 171 & -6.4 & -7.1 & -6.2 & -7.4 \\
\hline 11 & NA & 121 & 111 & -3.3 & -2.7 & -3.4 & -2.6 \\
\hline 12 & NA & 110 & 111 & -2.9 & -2.7 & -2.8 & -2.6 \\
\hline 13 & NS & 140 & 168 & -5.0 & -3.4 & -5.5 & -3.5 \\
\hline 14 & NA & 122 & 118 & -3.2 & -6.2 & -1.5 & -5.9 \\
\hline 15 & NA & 105 & 110 & -2.4 & -1.2 & -1.9 & -2.3 \\
\hline 16 & NA & 120 & 110 & -0.5 & -0.5 & -0.6 & -0.5 \\
\hline 17 & NA & 112 & 117 & -1.8 & -1.2 & -1.8 & -1.2 \\
\hline
\end{tabular}

NS-nutritional support, NA-not applicable.

$\mathrm{Z}$-score. Insufficient $\mathrm{BW}$ or $\mathrm{H} / \mathrm{L}$ is recorded according to the Z-score interval between -2 and -3 for the given age. Excessively insufficient BW or $\mathrm{H} / \mathrm{L}$ is detected when the $\mathrm{Z}$-score range is below -3 for the given age $[13,14]$. We have also investigated PEM in children with neurological impairments. More publications have shown PEM in children with CP $[3,5,6,10,11,16,21]$.

According to the review of Francesca Penagini et al., among 16 publications on dietary intakes and nutritional issues in neurologically impaired children, 10 publications show the results concerning NS in children with $\mathrm{CP}$, others with disabilities and delay in motor development [2]. Despite the fact that the problem of nutritive insufficiency in children with neurological impairments is being actively studied, the results of the studies differ [2].

Our study is original due to recruitment of children with congenital malformations of the brain. Furthermore, undernourishment in children with neurological impairment remains one of the major challenges to the health system for LMICs. Some publications demonstrated similar problem $[3,5,6,22]$. They have estimated that up to 200 million children are not reaching their development potential in LMICs [22, 23].

Our study demonstrates that growth trajectories in Ukrainian children with neurological impairment and undernourishment also depend on the knowledge level of the caregivers and medical staff due to loss of education and are similar to those obtained by Claudia Mary Donkor in Ghana [6].

A big step forward for our staff and our NonEnglish speaking country was to create the WHO a software "Anthro" in Russian. The results of our study influenced teaching of approaches to anthropometry by the staff and caregivers, time of feeding, energy needs and possibility to apply special nutrition which implies an informational and educational company in the community [6].

Moreover, our results show the issue of gastrostomy in children on local level [24]. These challenges mirror the reports of previous studies in similar patients [25].

The next special issue for discussion is anthropometry. The use of National Center for Health Statistics (US) for anthropometry of children with $\mathrm{CP}$ has been used in a large number of studies [26]. According to the review of Srishti Aggraval et al. only one study from Bangladesh applied the WHO standards for growth of children with CP $[26,27]$. The study included 37 children 1-11 yrs old with moderate and severe CP. The mean Z-score for BW was $-4.83 \pm 1.84$, mean $\mathrm{Z}$-score for $\mathrm{H} / \mathrm{L}$ was $-2.7 \pm 1.98$. We compared our total cohort, the mean of Z-score for BW was $-3.94 \pm 2.93$, and mean $\mathrm{Z}$-score for $\mathrm{H} / \mathrm{L}$ was $-3.12 \pm 1.98$ (Table 2). Our cohort was dominated 
by children with shunting. This indicates a more severe form of PEM and late attention to this problem in our children.

Energy consumption was calculated in 90 children age $2-13$ yrs old according to the type of CP (hemiplegia, diplegia, and tetraplegia) by Patricia Ayrosa C. Lopes et al. [28]. Similarly, to our study, the authors used the 24-hour recall method and a questionnaire of caregivers to calculate daily calorie intake, with the subsequent recommendation of its correction by the American Food Guide, we used the recommendations of ESPGHAN applying Schofield W.N. formula (1985) and conversing factors [9, 15]. Energy intake in Patricia Ayrosa C.Lopes et al. study was showed according to the age. We suppose that calories must be calculated in accordance with BW because children with neurological impairments have delay of BW.

Our results are also similar to those obtained by most researchers about the problems of swallowing in children with neurological impairments, and therefore, their meal time is lengthened [3, 6, 28, 29]. But we found that tubefed children had catastrophically shorter feeding time, which could lead to complications [30]. We suggest that there is a need in special studies for the same patients.

One of the most important issues regarding nutrition management in children with congenital malformations of brain is to apply NS. Just like the study, in which forty-five young patients aged between 2 and 26 years with severe neurologic impairment (GMFCS level V) were recruited, were identified with moderate or severe malnutrition, including the patients who received an intervention during a 6-month period, we have shown an improvement of nutritional status at the same period in our sample [31]. The difference was in the type of NS (gastrostoma vs nasogastric tube or orally). Whether the children received nutrition through a nasogastric tube or orally, for 6 months of nutritional support, we received positive results due to availability and utilization of nutrients from enteral formula, which was significantly better than the food prepared by the caregivers.

There were some inherent limitations associated with this study; firstly, sample size. Our model was based on single-center observational descriptive cross-sectional study and was limited by the time and number of patients in the East Ukrainian population with congenital malformations of the brain. Secondly, there was an age limitation (young children and preschoolers). There are very few prior researches and gaps in the studies relevant to young children with congenital malformations of the brain, which influenced the methodology of our study. Our study was limited by the recruitment of infants, which was not completely appropriate for GMFCS. We were unable to assess each factor on malnourishment, which may undermine the strength of the study.

\section{Conclusion}

The study demonstrated moderate and severe nutritional disorders in young children and preschoolers with congenital malformations of the brain: Z-score BW for age in total cohort was $3.2, \mathrm{H} / \mathrm{L}$ for age was -2.7 in LMICs. Its results differ from the previous studies that include children with CP. Late appointment of nutritional support to such children was demonstrated, as well as its effect on increasing growth and body weight. The importance of drawing up individual plans for the energetic consumption of the children with congenital malformations of brain with training of caregivers and rehabilitative and palliative team was shown. High-quality clinical trials are needed to better comprehend the methodology of nutritive support in children of any age with different neurological impairments.

\section{References}

1. Sangermano M, D'Aniello R, Massa G, Albano R, Pisano P, Budetta M (2014). Nutritional problems in children with neuromotor disabilities: an Italian case series. Ital J Pediatr., 40:61. doi: 10.1186/18247288-40-61

2. Francesca Penagini, Chiara Mameli, Valentina Fabiano, Domenica Brunetti, Dario Dilillo, and Gian Vincenzo Zuccotti (2015). Dietary Intakes and Nutritional Issues in Neurologically Impaired Children Nutrients, 7(11):9400-15.

3. Melika Melunovic, Feriha Hadzagic-Catibusic (2017). Anthropometric Parameters of Nutritional Status in Children with Cerebral Palsy. Mater Sociomed, 29(1):68-72. doi: 10.5455/msm.2017.29.68-72

4. WHO child growth standards and the identification of severe acute malnutrition in infants and children (2009). A Joint Statement, 11. Available from:https://www.who.int/nutrition/publications/ severemalnutrition/9789241598163/en/ 
5. Adamu Sa'idu Adamu, Umar Abba Sabo, Garba Dayyabu Gwarzo, Raymond O. Belonwu (2018). Nutritional Status in Cerebral Palsy: A Cross-Sectional Comparative Survey of Children in Kano, Nigeria. Nigerian Postgraduate Medical Journal, 25(3):156-160.

6. Claudia Mary Donkor, Jackie Lee, Natasha Lelijveld, Melanie Adams, Marjolein Meande Baltussen, Gifty Gyamah Nyante, Marko Kerac, Sarah Polack, Maria Zuurmond (2019). Improving nutritional status of children with Cerebral palsy: a qualitative study of caregiver experiences and community based training in Ghana. Food Sci Nutr., 7:35-43.

7. Skipper A, Ferguson M, Thompson K, Castellanos VH, Porcari J (2012). Nutrition screening tools: an analysis of the evidence. JPEN J Parenter Enter Nutr., 36:292-8

8. Van Bokhorst-de van der Schueren MA, Guaitoli PR, Jansma EP, de Vet HC (2014). Nutrition screening tools: does one size fit all? A systematic review of screening tools for the hospital setting. Clin Nutr., 33:39-58.

9. Romano C., van Wynckel M. (2017). Guidelines for the Evaluation and Treatment of Gastrointestinal and Nutritional Complications in Children with Neurological Impairment. JPGN., 65(2):242-264.

10. L Samson-Fang and KL Bell (2013). Assessment of growth and nutrition in children with cerebral palsy. European Journal of Clinical Nutrition, 67:5-8.

11. Tika Ermawati, Eddy Fadlyana, Dwi Prasetyo (2019). Estimation Body Height according to Tibia Length in Children with Cerebral Palsy Aged 6-12 Years in Bandung, Indonesia American Journal of Clinical Medicine Research, 7(2):48-52 doi:10.12691/ajcmr-7-2-3

12. Sarah M Phillips, Robert J Shulman, Kathleen J Motil, Alison G Hoppin. Measurement of growth in children Authors: Available from:https://www.uptodate.com/contents/measurement-of-growth-inchildren? source $=$ autocomplete \&index $=0 \sim 1 \&$ search $=$ growth $\% 20$ calculator,

Centers for Disease Control and Prevention. Available from:https://www.cdc.gov/ncbddd/ childdevelopment/positiveparenting/preschoolers.html

13. WHO Anthro Software. Available from:

https://www.who.int/childgrowth/software/en/

14. World Health Organization (1999). Management of severe malnutrition: a manual for physicians and other senior health workers. World Health Organization. Available from:https://apps.who.int/iris/ handle/10665/41999

15. Schofield WN (1985). Predicting basal metabolic rate, new standards and review of previous work. Hum Nutr Clin Nutr., 39(1):5-41.

16. Wood E., Rosenbaum P (2000). The gross motor function classification system for cerebral palsy: a study of reliability and stability over time. Dev Med Child Neurol., 42(5):292-6.

17. Godwin E.M., Spero C.R., Nof L., Rosenthal R.R., Echternach J.L (2009). The gross motor function classification system for cerebral palsy and single-event multilevel surgery: is there a relationship between level of function and intervention over time? J Pediatr Orthop., 29(8):910-5.

doi: 10.1097/BPO.0b013e3181c0494f

18. Cederholm T, Bosaeus I, Barazzoni R, Bauer J, Van Gossum A, Klek S (2015). Diagnostic criteria for malnutrition - an ESPEN consensus statement. Clin Nutr., 34:335-40.

19. Cederholm T (2017). ESPEN guidelines on definitions and terminology of clinical nutrition. Clinical Nutrition, 36:49-64.

20. Gomez F, Galvan RR, Cravioto J, Frenk S (1955). Malnutrition in infancy and childhood, with special reference to kwashiorkor. Adv Pediatr., 7:131-169.

21. Caselli TB (2017). Assessment of nutritional status of children and adolescents with Spastic Quadriplegic Cerebral Palsy. Arq Gastroenterol., 54(3):201-5.

22. Robert H. Bradley and Diane L. Putnick (2016). The role of physical capital assets in young girls' and boys' mortality and growth in low- and middle-income countries. Monogr Soc Res Child Dev., 81(1):33-59. doi: 10.1111/mono.12225

23. Grantham-McGregor S, Cheung YB, Cueto S (2007). Developmental potential in the first 5 years for children in developing countries. Lancet, 369:60-70. doi:10.1016/S0140-6736(07)60032-4.

24. Park RH, Allison MC, Lang J (1992). Randomised comparison of percutaneous endoscopic gastrostomy and nasogastric tube feeding in patients with persisting neurological dysphagia. BMJ, 304:1406.

25. Sleigh G., Brocklehurst P (2004). Gastrostomy feeding in cerebral palsy: a systematic review. Longer version of Arch Dis Child, 89:6:534-9. 
26. Srishti Aggarwal, Ravinder Chadha, Renuka Pathak (2015). Nutritional status and growth in children with cerebral palsy: a review Int J Med Sci Public Health., 4(6):737-44 doi: 10.5455/ ijmsph.2015.15012015192

27. Adams MS, Khan NZ, Begum SA, Wirz SL, Hesketh T, Pring TR (2012). Feeding difficulties in children with cerebral palsy: low-cost caregiver training in Dhaka, Bangladesh. Child Care Health Dev., 38(6):878-88.

doi: 10.1111/j.1365-2214.2011.01327.x. Epub 2011 Nov 15.

28. Patricia Ayrosa C. Lopes, Olga Maria S. Amancio, Roberta Faria C. Araujo, Maria Sylvia de S. Vitalle, and Josefina Aparecida P. Braga (2013). Food pattern and nutritional status of children with cerebral palsy Rev Paul Pediatr., 31(3):344-49. doi: 10.1590/S0103-05822013000300011

29. Caram AL, Morcillo AM, Pinto EA (2010). Nutritional status of children with cerebral palsy. Rev Nutr., 23:211-19.

30. Bodoky, G., \& Kent-Smith, L (2009). Basics in clinical nutrition: Complications of enteral nutrition. e-SPEN, 4(5).

Available from: https://doi.org/10.1016/j.eclnm.2009.05.003

31. Orel A. (2018). Nutrition of patients with severe neurologic. Impairment Radiol Oncol., 52(1):83-89.

Received: 30-Dec-2019

Accepted: 08-May-2020 